\title{
The Breast Unit of the Hospital S. João, Porto, Portugal
}

\author{
Maria João Cardoso \\ Breast Unit, Hospital S. João / Porto Faculty of Medicine, Porto, Portugal
}

The Breast Unit at the Hospital S. João went into service in 1997, with the main goal of better diagnosis and treatment for breast cancer patients. Now the number of new patients treated at the Unit per year rounds 250 . Our patients are frequently included in clinical trials.

As a group we always believed that it is of high importance to have the best multidisciplinary approach available. As a consequence we emphasize the importance of holding two meetings a week. The first is a diagnosis meeting, in which a surgeon, a radiologist and a pathologist revise the images and propose approaches to a better diagnostic work-up. The second is a treatment decision meeting. Besides surgeon, radiologist and pathologist, the medical and radiation oncologist take part in this meeting that is aimed at the best possible treatment decision for each patient. Our nurse specialist is always present in both meetings to maintain a permanent connection with our patients.

In 2002 we started using the sentinel node technique using blue dye with subareolar injection - initially in a validation trial and now as a regular procedure. With nearly 300 sentinel node procedures performed, our false negative rate stands below $2 \%$. Axillary clearance has been avoided in $71 \%$ of our patients. In our Breast Unit only patients with a negative axilla (clinical and ultrasound evaluation) are proposed for sentinel node biopsy. If there is any suspicious node on preoperative evaluation fine-needle aspiration (FNA) is always carried out.

In 2007 a new clinic for familial breast cancer risk was founded, to inform those patients and families who might have a familial risk. They are advised about the risk in general, and about hereditary breast and ovarian cancer syndromes. The clinic is equipped to search for mutations in the BRCA 1 and 2 cancer genes in those patients who fulfill the criteria for testing. Options for prevention and follow-up are offered for those considered at higher risk for breast or other cancers.

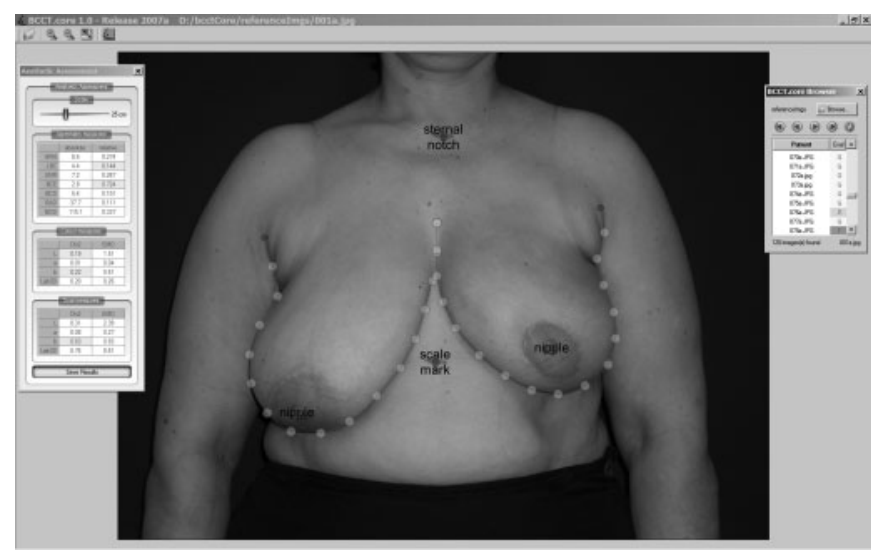

Fig. 1. BCCT.core screen.

As the Hospital S. João is a University Hospital, where the Porto Faculty of Medicine resides, the Breast Unit has a natural and straight bond with pre-graduate and post-graduate teaching. Participation in international conferences and clinical investigations and publication of the results as well as the development of new techniques are also part of our work.

The final aesthetic result of breast cancer treatment was one of our most important concerns. An investigation involving several countries and a fruitful cooperation with Prof. Jaime Cardoso, an expert engineer of image analysis from INESC (Institute for Systems and Computer Engineering) Porto, led to the development of a tool for objective evaluation of the cosmetic results of breast conserving treatment, called BCCT.core (Breast Cancer Conservation Treatment.cosmetic results, fig. 1). The purpose of the BCCT.core software is to simplify and standardize the esthetical evaluation of breast conserving surgery. This innovative tool allows to quickly and accurately automate the measurement of all the well-known

\begin{tabular}{|c|c|c|}
\hline KARGER & (c) 2007 S. Karger GmbH, Freiburg & $\begin{array}{l}\text { Maria João Cardoso, MD, PhD } \\
\text { Breast Surgeon, Breast Unit Coordinator }\end{array}$ \\
\hline $\begin{array}{l}\text { Fax +49761 } 4520714 \\
\text { E-mail Information@Karger.de } \\
\text { www.karger.com }\end{array}$ & $\begin{array}{l}\text { Accessible online at: } \\
\text { www.karger.com/brc }\end{array}$ & $\begin{array}{l}\text { Hospital S. João / Porto Faculty of Medicine } \\
\text { Alameda Prof. Hernani Monteiro } \\
\text { 4200-319 Porto, Portugal } \\
\text { E-mail mjcard@med.up.pt }\end{array}$ \\
\hline
\end{tabular}


indices and objectively quantify the esthetic results, discriminating between four categories (excellent, good, fair, and poor). Users will find BCCT.core especially useful for reporting quickly and accurately results that were, up until now, time consuming, requiring the proficiency on several tools. A second major functionality of the BCCT.core workstation is the capability to automatically translate the set of measures performed on the digital images into an overall objective classification of the esthetical result. This classification is reported automatically to the user and saved in a database. This enables an effective comparison of different medical teams. The BCCT.core software is now available for EUR 250 as a downloadable tool, obtained after signing a license agreement from our webpage (http://breastcancer.up.pt/). It is currently used by other groups for evaluation of their own cosmetic results. The development of the BCCT.core tool and the interest demonstrated by others led to new approaches now directed at other interventions in breast surgery like oncoplastic operations. 